\title{
Discussion
}

\section{Toward an Epistemological Luddism of Bioethics}

\author{
Susan E. Kelly
}

In the decades since its emergence, bioethics has become successfully integrated, institutionally and culturally, into contemporary processes of biotechnological production. Its success is in large part the result of the development within American bioethics of a strong principlist form that has had considerable influence on bioethics developments regarding biotechnology governance internationally. This article presents a critique of bioethics, drawing on insights from early work of Langdon Winner, as 'human technique' - organized to adapt human needs and purpose to requirements of biotechnological systems. From Winner it is suggested that present technological systems give rise to an ethics that is appropriate to their ends, and the norms, social relations, and values embedded in those systems are naturalized as central to life. Bioethics has not developed reflexivity concerning its relationship with technology, a reflexivity that is necessary for development of an ethics of technology that has the capacity to critically engage its subject. Winner suggests, somewhat whimsically, a process of "epistemological Luddism," or the conscious dismantling of the relations of technology, as a mechanism through which human autonomy with regard to technological systems might be recovered. Implications for a reorientation of bioethics following this suggestion are examined.

Keywords: bioethics, biotechnology, Langdon Winner

Finally, I could suggest a supremely important step - that we return to the original understanding of technology as a means that, like all other means available to us, must only be employed with a fully informed sense of what is appropriate. Here the ancients knew, was the meeting point at which ethics, politics and technics came together (Winner, 1977: 327).
In the 1970s Langdon Winner raised prominent arguments about the political nature of technological choices, choices he claimed hold profound implications for liberty, power and our sense of being human. These arguments resonate with early concerns in contemporary bioethics about societal implica- 
tions of developments in the life sciences and biotechnology. Nonetheless, while Winner's Autonomous Technology (1977) and the later Whale and the Reactor (1986) are classic statements addressing relationships among ethics, technology and politics, they have received scant attention in debates within, and about, bioethics. This is unfortunate; ethical assessment has become integral to processes of biotechnological production (Glasner and Rothman, 2001). As bioethics has emerged as an increasingly institutionalized (and multiple sited) response to concerns of the kinds raised by Winner, it has failed to develop as a substantive critique of biotechnology. Bioethics - understood as applied ethics discourse and practice located at institutional intersections of society, biomedicine and the life sciences - has in many instances become a new technology in ways that are not sufficiently recognized and explored. Winner's work thus offers possibilities for critical examination of bioethics through a reflexive scepticism about evolving ethics/ technology relations. Although Winner does not explicitly address applied ethics as a mode of decision-making about technology, he does offer a 'modest proposal' - epistemological Luddism - a systematic 'dismantling' of problematic technologies to study their interrelationships and relevance to human needs. Taken together, his arguments suggest examination of the location of bioethics within the ensemble of modern biotechnological systems, the form of ethics that emerges from particular biotechnological systems, and the ability of such ethics to reflect upon human needs. The contemporary field of bioethics emerged several decades ago when pos- sibilities of science and technology to alter profoundly, not merely to know, the world became the object of theological, political, and cultural discourse. Developments including reproductive, life saving and life extending technologies (heart-lung and renal dialysis machines), expanding possibilities of the "new biology" and later, human biotechnologies (including genetic engineering, advanced drug therapies and enhancements, and bioengineering), inspired wide ranging questions about the desirability and wisdom of technological intervention into fundamental human social relationships and the future condition of humankind. It was a moment in which the social transformative and regulatory potential of biotechnology were at the centre of important debates involving scientists, philosophers, and theologians (Dobzhansky, 1967; Etzioni, 1973; Kass, 1972; Lappé, 1972; Ramsey, 1970; Sinsheimer, 1969), as well as debates in political theory about society/ technology relations (Ellul, 1964; Heidegger, 1977; Marcuse, 1964; Winner, 1977).

A number of critics (Callahan, 1993; 1998; Evans, 2002), have argued that in the intervening decades bioethics has moved toward separation from substantive questions of human ends to focus narrowly on fitting together emerging technological means and a limited range of values and concepts, systematized in regulatory practices and procedures. In its evolution away from substantive debate about human ends toward which biotechnology, among other means, might be employed, bioethics has come to resemble what Jacques Ellul (1964; see also Helén, 2002: 132) identified as "human technique" - a form of social or- 
ganization adapting the human to the requirements of technology. Specifically, bioethics has come to be a means of fitting 'the human' to the ends of biotechnology rather than a discourse or mechanism through which appropriate human needs and ends, appropriate to governing the construction of biotechnological systems, are sought. The shift to technique can be seen, for example, in the advancing of procedural over substantive requirements of human subjects protections and privacy rights across a range of practises (from human tissue collection and storage to drug trials). The transformation has been described as a shift from "thick" substantive to "thin" formal rationality by sociologist John Evans (2002) and as a movement from a prophetic to a regulatory ethics by bioethicist and sometime critic Daniel Callahan (1993; cited in Moreno, 1995). Whatever the specific terms of critique, it appears to a number of observers that bioethics has ceded to biotechnology much of its power to shape human activity and its meaning.

It is important to consider how this might have come to be the case, and to examine whether, and in what ways, bioethics might become a substantive exercise of 'insight and commitment' through which to recover a rich sense of human ends vis a vis biotechnological systems (Winner, 1977: 323). A critique of contemporary ethics of biotechnology may emerge from the pessimism Winner himself appears to express concerning formal, or specialist, ethics: he argues against an ethics that is either too abstracted from real possibilities for action as they are constrained by the political economy of socio-technical systems, or too bogged down in details of one tech- nology to grapple with the systemic character of large-scale technological institutions (Winner, 1977: 319). Further, Winner's critique supports the claim that, as modern technologies have politics (technology as legislation), they may also give rise to ethical systems that correspond to and sustain them.

Unlike conservative bioethical critics of biotechnology, exemplified by ethicist Leon Kass, Winner is concerned first not with ends (for Kass, "human dignity") but with the capacity to determine them; he is concerned with the subversion of human autonomy of consciousness and action by technology acting autonomously through the organization of the world to the requirements of technical instrumentality. He describes a process of 'reverse adaptation' in which present technological systems become the mould to which human ends are adjusted, and the norms, social relations, and values embedded in those systems are naturalized as central to life (Winner, 1977: 229). Such technical rationality is, in this critique, blind to itself, requiring reflection through other forms of thought (Feenberg, 1999: 207). Bioethics as a particular form of commentary on technology has been successful both institutionally and culturally in its involvement with life sciences and biotechnology. However, to the extent that it fails in reflection on problematics of human autonomy, technical instrumentality, and its own "naturalized" location within social relations, an ethics of biotechnology will fail in the project of human ends. Such an ethics runs the danger of taking the form of technique, or mere regulatory methodology. Drawing from Winner and others within the philosophy of technology, an alternative, substantive 
ethics of biotechnology is suggested that is reflexively attentive to the organization of the human world to the requirements of biotechnological systems, and current and possible positions of ethical deliberation within them.

\section{Bioethics as Human Technique}

Applied ethics has come to play a significant role in how scientists, governments and publics frame their engagement with science and technologies. Ethical accountability, means-ends deliberations, and the enshrinement of interest group, state, and professional values concerning the development, regulation and uses of scientific knowledge and technologies have become nearly inextricable from the processes through which these are produced. Attention to 'the ethical' in science and technology now appears in multiple sites of knowledge production, from governmental policy bodies, to academic institutions, to commercial organizations. As such, bioethics is a resource useful to multiple actors in negotiations about the constitution of research objects and their policy frameworks. The reflexive turn toward ethics in life science policy is in part a response to issues of legitimacy: public mistrust of science and technology and a perceived need to bring publics into discussions about scientific innovation.

These discussions are dominated by the American model of bioethics - usually characterized as reductionist, liberal, rational-technical, and principalist- which has to a large extent successfully institutionalised a narrow range of ethics-related discourses and practices concerning biotechnology. The affinity of this form of ethics for bureaucratic structures, and its instantiation as a form of expertise, have facilitated its entry into multiple locations of life science and biotechnology policy, administration and production (Evans, 2002; Kelly, 2003). Bioethics is currently engaged in a broad range of policy, research and educational forums internationally, constituting an extensive network of expertise, regulatory mechanisms, products and artifacts (for example, internet searches for bioethics and biotechnology yield information on hundreds of bioethics organizational locations across levels of biotechnology production and governance).

The dominant form of bioethics has been challenged from feminist and multicultural positions, among others, but these challenges have for the most part engaged the dominant model on its own terms while widening its application and acceptability. In the international arena, in which biotechnological choices serve dual economic and political instrumentalist ends, bioethics remains engaged with the dominant form while reflecting local interests. For example, science and technology ethics discourses being developed in countries including Japan and China exhibit both an effort to build upon and participate in a broader community of ethics concerns, one that is largely dominated by the liberal American model, and to create unique models of research ethics that build upon the configuration and participation of stakeholders within each national context (see Morioka, 1995). International ethics bodies, such as UNESCO seek to harmonize broad bioethical statements reflecting somewhat different national concerns, while pro- 
liferating policy guidance statements on issues including stem cells, cloning, and DNA data bases. Responding to issues of public trust and regulatory demands of state knowledge production partners, the biotechnology industry increasingly includes bioethics advisory units within corporate structures (e.g., Affymetix; see also Dhanda, 2002).

Bioethics arose in the 1960s in response to the perceived potential of emerging life sciences to alter the future human condition, and many of its initial practitioners engaged questions of human ends and the relationship of rapidly emerging biotechnological means to achieve them or subvert them with their own. They challenged, to some extent, the potential 'autonomy' of emerging technologies - of profound changes in the nature of human control over technology and of human futures. Developments including renal dialysis, organ transplantation, artificial respiration, and advances in human reproductive technologies (including birth control, medically safe abortions, prenatal diagnosis, and in vitro fertilization), were seen by a number of scientists and theologians to pose challenges to existing religious and broader societal moral and world views concerning reproduction, family, individual conscience and sources of moral authority. Birth control technologies drew particular interest not only from religious institutions embattled by societal modernization, cultural change, and their waning moral authority, but also from governments searching for solutions to what demographers warned was a worldwide population explosion.

Callahan, a founder in 1969, of the Institute of Society, Ethics and the Life
Sciences (now the Hastings Center) was among a number of theologically oriented intellectuals who struggled with these questions. Joseph Fletcher, an Episcopalian theologian who later rejected religious beliefs, in Morals and Medicine (1972/1954) and later, The Ethics of Genetic Control (1974), argued a view of modern medical science and technology as liberating human beings from nature, claiming that we are most expressive of our humanity when we are making and using technologies. Teilhard de Chardin (1959; 1964), among others, argued that the knowledge of humanity gained through science could be used to the betterment, even re-creation, of humankind. Geneticist Theodosius Dobzhansky took this view in works such as the Biology of Ultimate Concern (1967) and Mankind Evolving (1962: $346)$, writing that "hope lies in the possibility that changes resulting from knowledge may also be directed by knowledge".

Ethicist Paul Ramsey engaged these debates from a perspective that sought to raise questions of limits as well as potentiality:

We need to raise the ethical questions with a serious and not a frivolous conscience. A man of frivolous conscience announces there are ethical quandaries ahead that we must urgently consider before the future catches up with us... By this he often means that we need to devise a new ethics that will provide the rationalization for doing in the future what men are bound to do because of new actions and interventions science will have made possible. By contrast, a man of serious conscience means to say in raising urgent ethical questions that there may be some things that man should never do. The good things that men do can be made complete only by 
the things they refuse to do. (Ramsey, 1970: 122-123)

Central to the objectives of the emerging ethical discourse was explication of the meaning and possibilities of human freedom - an end, however disparately defined - given possibilities raised by human biotechnology. At least three forms of substantive argument emerged in these concerns: a) philosophies relating technology as human-directed means to the (often teleological) evolution of human potential and freedom, $b$ ) theological and secular reflections on implications of emerging technologies for fundamental human values and the social institutions in which they are embodied, particularly family/kinship, and c) concerns about knowledge and technology out of control - knowledge that accumulates faster than the human wisdom to direct or control the consequences of its application.

From these early substantive concerns, bioethics has trended toward formal rationalization as it has increasingly become a policy-relevant and engaged practice (Evans, 2002). Biomedical science and research had become "technology requiring legislation" (Winner, 1977: 317 ), and the ethics community filled the role. From initial statements concerning the new ethics in the life science policy, to its rapid institutionalization in public policy affairs, the emphasis on achieving societal-level rules in an explicitly value-defined arena led to the reduction of substantive value positions to a set of abstract principles that might hold authority across a range of particularist value-commitments. The trend followed the broadening of the "bioethics movement" from academic and professional forums (including the establishment of an increasing number of societies and institutes dedicated to bioethics) toward institutionalizing ethics within biomedical science policy, particularly as advisory in regulation of biomedical research.

In the US, the first major steps toward institutionalization were congressional hearings on human experimentation and biomedical and behavioral research leading to the establishment in 1974 of the National Commission for the Protection of Human Subjects of Biomedical and Behavioral Research. The National Commission was mandated to develop a regulatory framework for human experimentation that would be enacted through public rulemaking procedures. The resulting explication of principles, issued as the Belmont Report, became an influential framework for contemporary bioethics regulation emphasizing risk, benefit, and justice concerns. Following the liberal pluralist model, the National Commission and subsequent panels sought to represent consensus, at least in the outcome of deliberation, in their policy statements.

The Belmont framework has solidified into the basic principles of bioethics (autonomy, beneficence, nonmaleficence and justice) (Childress, 1989; Beauchamp and Childress, 1989), and expanded in application from human experimentation to practices of clinical medicine, where they inform the deliberations of hospital ethics committees as well as work in other institutional locations where bioethics has taken hold. It significantly shapes the work of institutional review boards in their examination of human subjects research protocols. The same framework has continued to shape subsequent debates about the range of 
scientific and technological issues that have come under bioethical jurisdiction. Principles, such as beneficence, have become ends that are attachable to any biotechnological means (Evans, 2002: 151).

Regulatory ethics developed further in the US through the President's Commission for the Study of Ethical Problems in Medicine and Biomedical and Behavioral Research (established in 1978), in reports that explicated a theory of informed consent and addressed problematics of human genetic engineering. Evans (2002) identifies the latter report as transitioning debates from substantive, ends-reflective concerns to a selected range of means and ends questions defined largely through scientific and bioethical discourses and interests. Later commissions in the US, such as the National Bioethics Advisory Commission, in its report on human cloning (1997), retained explicit emphasis on safety over ends questions, reflecting a broader blurring of ethical and safety issues in discussions of biotechnology.

The replacement of substantive ends debates by proceduralism in bioethics has been facilitated by a dominant emphasis on autonomy (as exemplified by replacement of Callahan's (1973) early "tyranny of survival" by patient autonomy in clinical ethics). Autonomy ethics is unpinned by the distinctive construction of the self/body in the liberal philosophical tradition, a tradition that conceptualizes ethical reasoning as being about the rules of conduct for individual human interaction, what one can legitimately do to others and expect in return. The liberal tradition seeks to regulate competing interests, desires and passions under a coherent set of rules and within a given socio-political and economic context.

In the tradition of Western liberal political thought, liberal selves have as property a body; it is their tool for survival and further, governs their relationships with others. It is private in a way that the environment, or more generally nature, is not. Contemporary autonomyfocused ethics reflects the distinctive liberal construction of the self-body as property and narrows rather than expands the locus and direction of moral agency, responsibility, and vision. A variety of critiques of the liberal property notion, however, have emerged within bioethics (Emanuel, 1991; Loewy, 1993; Nelson, 1994). Of particular relevance, philosophers concerned with technology, including Hans Jonas (1984), have posited an alternative path for bioethics - an ethics of responsibility to future humans, or projected visions of a common material and moral life. Nonetheless, these critiques, and their translation into mechanisms or procedures for an ends-oriented bioethics, are minimally reflected in the dominant, proceduralist bioethical framework for technological decision-making.

Autonomy ethics expresses a tension between individuals as subjects of rights and objects of commodification (or put another way, between the body/self as property and the body/self as resource for biotechnological systems). While bioethicists have largely resisted commodification of body parts as property of individuals - in such instances as organ, egg and blood donation - it has had little to say about the broader biotechnological system that rests, significantly, upon commodification of 'de-propertied' body parts. More broadly, within bioethics, biotechnologies are concep- 
tualized as privatized and tools for individual body/property achievements rather than as systems engaging societal ends. Bioethics, in the tradition of liberal thought, instantiates the "appropriate" political and moral position of the subject vis a vis liberal economic market ideologies and large-scale technological systems of production and consumption (Jennings, 1998; Caufield, 1999). Biotechnologies are always potential 'resources of the self... the means of realizing individual will and purpose' (Jennings, 1998: 258).

A reductionist, autonomy ethic is ideally suited to fitting human agency to the requirements of technological systems the robustness with which practices of informed consent are maintained as evidence - but has not proven conducive to engaging the moral nature of technologies, or technological systems, themselves. As Lappé (1972: 415) observed, "man himself becomes the object of the technique".

These observations alone are not new; alternatives to autonomy ethics have appeared as communitarian strains in bioethics (drawing on the work of political theorists including Alasdair MacIntyre, Michael Sandel, Charles Taylor and Michael Walzer). Communitarian ethics may go some way toward elucidating conditions for a deliberative discovery of appropriate ends as a basis for technological choice. It does not, however, provide a compelling critique of biotechnology acting upon, organizing and adapting social relations and values to the demands of technological systems.

\section{Epistemological Luddism and Alternative Bioethics}

Technologies require ethical and political choices because, "(d)ifferent ideas of social and political life entail different technologies for their realization" (Winner, 1977: 325, italics in the original). It is reasonable to suggest that mechanisms for identifying such ideas might involve an applied ethics. However, current bioethics does not appear to meet the challenge. Winner offers no clear "way out" or methodology for how a transformation in the ethical and political framing of biotechnological problematics might occur. Technology for Winner does not create the conditions for its own control/defeat; does not, as envisioned by Marx, create agents able to transform social relations. Perhaps more importantly, technology does not give rise to an ethics that will lead necessarily to appropriate reflection on its subject.

Nonetheless, Winner offers a "modest proposal" toward a method of inquiry into problematic technologies, a method he termed "epistemological Luddism":

(T)echnologies identified as problematic would be taken apart with the expressed aim of studying their interconnection and their relationships to human need... The method of carefully and deliberately dismantling technologies, epistemological Luddism if you will, is one way of recovering the buried substance upon which our civilization rests. Once unearthed, that substance could again be scrutinized, criticized, and judged. (Winner, 1977: 330)

Winner's is not Luddism in the traditional sense - the destruction of technological apparatuses - but an inquiry into the conditions certain technologies impose on modern social life. It suggests a 
reorientation of inquiry to which bioethics might be turned, considering at least the following types of questions about biotechnologies: "(1) the kinds of human dependency and regularized behavior centering upon specific varieties of apparatus, (2) the patterns of social activity that rationalized techniques imprint upon human relationships, and (3) the shapes given everyday life by the large-scale organized networks of technology" (Winner, 1977: 331).

These are not questions central to dominant forms of bioethics, which as I have argued ask questions more suited to organizing human behavior and dependencies to fit a sense of what is required by technologies (e.g., privacy protection, risk/benefit assessments, informed consent, respect for persons). However, a bioethics project that takes the Luddite questions seriously, given its current institutional and cultural success, presents the possibility of a strong critique of biotechnologies that seeks to harness such systems to human ends. Such a bioethics begins with identification of its location within the social activities patterned by biotechnological systems ('rationalized technique'), the social relations and normative structures it inculcates, the origins of its questions, and the interconnections and dependencies with technological systems these questions represent. To contemplate such a bioethics entails distinguishing among ethics as a form of social relations embedded within and emergent from socio-political processes of technology; ethics in the form of specific institutions, specialized language and discourse, and social practices; and, finally, possibilities of achieving through bioethics critical reflection on the nature of biotechnological systems.

First, consistent with Winner's (1977: 324) argument that modern technique legislates the conditions of human existence is an understanding of ethics as the normative framework emerging from and influencing the social relations of politics and technology: systems of obligation and expectation, identification and prioritization of values, and appropriate forms and scope of human agency. Ethics in this sense is a form of argumentation that naturalizes systems of meaning and action attached to biotechnological objects (what Brian Wynne (2002) refers to as processes of cultural objectification or reification of human meanings and subject-identities). Ethics is embedded within both politics and technology and if technologies have politics, they also have ethics. Current ethics of biotechnology are ultimately practices of reverse adaptation: "the adjustment of human ends to match the character of the available means" (Winner, 1977: 229). Similarly, Feenberg (2002: 206) locates ethics in processes of 'secondary instrumentalization': a form of mediation that provides technical objects with secondary qualities that seamlessly embed them within appropriate social contexts. Winner points to the danger of failing to be reflexive about ethics as fitting a mediating role - the extent to which emergent ethics as socio-political relations of technology are or are not consciously and deliberatively identified, made explicit, and made the object of action. Uncritical attention to emergent ethics of technological systems constitutes, for Winner, ethical somnambulism. By contrast, technological ethics as conscious reflection on the nature and human require- 
ments of technological systems may be seen as ideally instantiated in reflexive, grounded examination of socio-technological relations and normative commitments accompanying technologies and their politics.

Second, ethics cannot be divorced from the real politic of action, nor from the broader philosophy of technology that reveals its interdependence with social relations and the polity. Winner argues that while contemporary calls for more ethically aware scientists and engineers are laudable, they will do little good without attention to the contexts in which such moral sensibilities are to operate, "the context in which the most powerful opportunities for action are made available" (Winner, 1977:305), and in which the genuine requirements of moral responsibility are tested. Moral sensibility becomes technique when employed by producers of biotechnology to meet public expectations of ethical accountability. Further, ethics as a way of rendering reality implies strategies and activities of governance of biotechnologies. It is a parallel activity to risk assessment - in constructivist accounts risk models and the controversies they may engender reflect different assumptions about a technology and the social relations integral and normative to it (Levidow and Carr, 1997; Levidow et al., 1997).

Similarly, Winner is critical of proposals of a utopian vision or "new ethic" for technical and scientific practice in our culture, such as those advocating a nonanthropocentric perspective on humans/ nature or moral liberation through scientific and technical mastery of nature, particularly human nature. Calls to a new ethic that suggest "vast revolutions in consciousness where good sense and moderation might do" (Winner, 1977: 133) beg the practical problem of how such revolutions in societal consciousness are to take place. Rather than appealing to a new ethic, Winner suggests a closer exploration of social relations underpinning technology itself, asking how these might have gotten out of hand. The strategy toward which he points - excavating the social processes and impulses that led us to our current relationships with technology-may lead us to a better understanding of what sense of limits we operate, how they arose, and how they might preclude other paths (Winner, 1977: 134).

The current form of bioethics has been less than successful at a range of tasks that might constitute an assessment of problematic biotechnologies and lead to more appropriate application to human ends. It has not been conducive to projects seeking to broaden and democratise participation in biotechnology assessment, particularly as it has taken on qualities of specialized and formalized knowledge and knowledge holders (Kelly, 2003).

It has been characterized by 'technology blindness,' an insufficient insight into the moral significance of technological artefacts as they emerge from the intimate intertwinement of technology and society; bioethics has thus been unable to cope adequately with the highly dynamic character of modern technological culture (Keulartz, 2004). Where bioethics is concerned with the governance of human relations as conditioned by biotechnological developments, and the deliberation and application of normative rules for such governance, it has not been adequately attentive to the 
conditioning of normative commitments by technological culture - the problematic raised by Winner in the notion of autonomous technology. It has tended to reinforce attention to what Wynne (2002) has termed 'back-end scientific questions about consequence or risks,' deflecting or excluding more reflexive questions about 'front end' commitments of technological innovation. The forces - the social relations - shaping these commitments remain outside the boundaries of bioethical scrutiny and in problematic relation to a bioethics deeply embedded within biotechnological systems.

\section{Epistemological Luddism and Bioethics: Dismantling the Edifice}

It is here that Winner's modest proposal becomes relevant. If bioethics is identified as technique, we might take up Winner's somewhat whimsical suggestion concerning a way out of the binds of autonomous technology - epistemological Luddism - as a strategy for bioethics as human technique:

As we have already noted, is not the fundamental business of technics that of taking things apart and putting them together? One conceivable approach to tackling whatever flaws one sees in the various systems of technology might be to begin dismantling those systems. This I would propose not as a solution in itself but as a method of inquiry. The forgotten essence of technical activity, regardless of the specific purpose at hand, might well be revealed by this very basic yet, at the same time, most difficult of steps. (Winner, 1977: 330, emphasis added)

An ethic (in the senses both of strategy and normative framework) that can be derived from Winner is one in which the goal is to liberate human autonomy, not from the tyranny of a specific technology, but from the distorted political nature of the socio-technical systems of which individual technologies are constitutive elements. In a positive sense, engaging bioethics in this task would build upon its institutional and cultural success as a resource in governance strategies of biotechnology. It would, however, begin with an alternative set of assumptions about the nature of its task.

The first assumption is the relationship of bioethics to biotechnology: bioethicists would adopt a reflexive attitude toward the origins and location within encompassing biotechnological systems of the ethical frameworks in which they work; that is, the extent to which bioethics reflects or instantiates an ethic that has emerged from technology and politics as normative structures supporting forms of social relations appropriate to, and conditioned by, technological systems. This assumption entails recognizing the systemic character of biotechnologies; that the realization of technologies involves the interaction, coordination or integration of different components of what are generally recognized as sociotechnical systems (Radder, 1996).

A second step is reorientation from an expert practice that operates relatively closed deliberative strategies and discourses within existing frameworks of biotechnological systems to an ethics that seeks to identify and evaluate decision-making strategies appropriate to governance of biotechnological systems. Bioethics should thus actively seek the opening of deliberative possibilities about the nature of biotechnological systems and what they entail for multi- 
ply sited actors. This assumption follows from the insight that technologies are brought into being through particular practices, by particular actors, for particular users, and at particular times (Radder, 1996). Normative evaluation of technological systems, evaluation of their appropriateness as means toward valued human ends, must engage strategies that are similarly multi-sited, involving information and insight from producers and users across socio-technical systems. The strategy is all the more pressing as biotechnological systems globalize, creating vastly different effects for actors and environments located differently within system networks. For example, bioethics can no longer merely engage an ethics of biotechnology from the position of Western producers and users, but must draw information from interconnected locations of resource (e.g., tissue) sourcing, artefact (e.g., pharmaceutical) production, and various forms of distribution.

A third step is reorientation from evaluation of technological artifacts or objects (e.g., stem cells and gene based therapies, DNA data banks) and subjects (e.g., autonomous agents) to evaluation of the quality of the 'natural, personal, and socio-cultural world in which the people involved will have to live in order to successfully realize the technologies in question' (Radder, 1996: 150). Again, such a reorientation would, for example, turn analysis to the global dynamics of research and development, production and user regimes of pharmaceuticals and the impacts of these dynamics on multiply sited actors, environments, meanings and subjectivities. It would entail not moral choices about specific research or intervention strate- gies, but would provide information on the basis on which to evaluate quality of life impacts broadly understood, and the normative commitments (to specific organization of social relations, to specific distributions of benefit/harm, to tolerance of failure) inherent in the realization of a technological system. These are not merely questions of autonomy, beneficence or justice, but of choices and accountability in the construction and legitimation of biotechnological systems. They are questions that seek broadly and empirically to grapple with the implications of biotechnological systems for human life and its futures.

It is clear that the present disciplinary form of bioethics alone is not appropriate to engage the heterogeneous nature of biotechnological systems. Rather, bioethics as a form or framework for inquiry, analysis and governance would synthesize ideas and methods from disciplines including political economy, science and technology studies, anthropology and sociology. By engaging actors from throughout technological systems, input into evaluative processes would incorporate knowledges of diverse stakeholders, connecting diverse localities, and building capacities for broader, grounded participation. The boundaries of biotechnological systems would emerge through such an analysis, as would the interconnections of systems.

Bioethics emerged as a potentially substantive discourse or critical philosophy of technology, and as a 'movement' has seen shifts in consciousness regarding the making, governance and accountability of science and technology. The very institutional and cultural success of the bioethics project, and the importance of debates about biotechno- 
logical developments, suggests that bioethics is suboptimized as mere human technique. There is, as Winner suggests, danger in an ethics of biotechnology that fails in reflexively examining its relationship to technological systems. Alternative possibilities of bioethics as method through which the dynamics and human effects of biotechnological systems are investigated and reflexively governed can make significant use of the current interest in querying 'the ethical' in technological developments. But there is an urgent need for bioethics to grapple with the question of technology - the nature, logics, complexities, boundaries and requirements of the biotechnological systems we have developed and are developing, and the conditions under which an ethics might offer insights into their relevance to human need.

\section{References}

Beauchamp, T.L. \& Childress, J.F.

1989 Principles of Biomedical Ethics. $3^{\text {rd }}$ Edition. New York: Oxford University Press.

Callahan, D.

1973 The Tyranny of Survival, and Other Pathologies of Civilized Life. New York: Macmillan.

1993 "Why Americans Accepted Bioethics." Hastings Center Report, Special Supplement, 23, 6: S8-S9.

1998 False Hopes: Why America's Quest for Perfect Health Is a Recipe for Failure. New York: Simon \& Schuster.

Caufield, T.

1999 "Regulating the Commercialisation of Human Genetics: Can We Address the Big Concerns?" Pp. 149-161 in Thompson \& Chadwick (eds.), Genetic Information. New York: Kluwer Academic/Plenum Publishing.

Childress, J.F.

1989 "The Normative Principles of Medical Ethics.” Pp. 27-48 in Veatch (ed.), Medical Ethics. Boston: Jones and Bartlett.
Dhanda, R.K.

2002 Guiding Icarus: Merging Bioethics with Corporate Interests. Hoboken NJ: Wiley-Liss.

Dobzhansky, T.

1962 Mankind Evolving: The Evolution of the Human Species. New Haven: Yale University Press.

1967 The Biology of Ultimate Concern. New York: New American Library.

Ellul, J.

1964 The Technological Society. New York: Random House.

Emanuel, E.J.

1991 The Ends of Human Life: Medical Ethics in a Liberal Polity. Cambridge, MA: Harvard University Press

Etzioni, A.

1973 Genetic Fix. New York: Macmillan.

Evans, J.

2002 Playing God? Human Genetic Engineering and the Rationalization of Public Bioethical Debate. Chicago: University of Chicago Press.

Feenberg, A.

1999 Questioning Technology. London and New York: Routledge.

2002 Transforming Technology. New York: Oxford.

Fletcher, J.F.

1972/1954 Morals and Medicine: The Moral Problems of: The Patient's Right to Know the Truth, Contraception, Artificial Insemination, Sterilization, Euthanasia. Boston: Beacon Press.

1974 The Ethics of Genetic Control: Ending Reproductive Roulette. Garden City, New York: Anchor Press.

Glasner, P. \& Rothman, H.

2001 "New Genetics, New Ethics?: Globalisation and its Discontents." Health, Risk \& Society 3(3): 245-259.

Helén, I.

2002 "Risk and Anxiety: Polyvalence of Ethics in High-tech Antenatal Care." Critical Public Health 12(2): 119-137.

Heidegger, $\mathrm{M}$.

1977 The Question Concerning Technology. Trans. W. Lovitt. New York: Harper and Row. 
Jennings, B.

1998 "Autonomy and Difference: The Travails of Liberalism in Bioethics." Pp. 258-269 in DeVries \& Subedi (eds.), Bioethics and Society: Constructing the Ethical Enterprise. Upper Saddle River, NJ: Prentice Hall.

Jonas, $\mathrm{H}$.

1984 The Imperative of Responsibility: In Search of an Ethics for the Technological Age. Chicago: University of Chicago Press.

Kass, L.

1972 “New Beginnings in Life." Pp. 15-63 in Hamilton (ed.), The New Genetics and the Future of Man. Grand Rapids, MI: William B. Eerdmans.

Kelly, S.E.

2003 "Public Ethics and Publics: Consensus, Boundaries, and Participation in Biomedical Science Policy." Science, Technology \& Human Values 28(3): 339-364.

Keulartz, J.

2004 "Introduction." Techné: Research in Philosophy and Technology 7(3). http:/ /scholar.lib.vt.edu/ejournals/SPT/ v7n3/keulartz.html

Lappé, $\mathrm{M}$.

1972 "Moral Obligations and the Fallacies of 'Genetic Control.” Theological Studies 33(3): 411-427.

Levidow, L. \& Carr, S.

1997 "How Biotechnology Regulation Sets a Risk/ethics Boundary" Agriculture and Human Values 14(1): 29-43.

Levidow, L., Carr, S. von Schomberg, R. \& Wield, D.

1997 "European biotechnology regulation: framing the risk assessment of a herbicide-tolerant crop" Science, Technology and Human Values 22(4): 472-505.

Loewy, E.H.

1993 Freedom and Community: The Ethics of Interdependence. Albany, NY: Statue

Marcuse, $\mathrm{H}$. University of New York Press.

1964 One-Dimensional Man. Boston: Beacon.

Moreno, J.D.

1995 Deciding Together: Bioethics and Moral Consensus. New York, Oxford: Oxford University Press.
Morioka, M.

1995 Bioethics and Japanese Culture: Brain Death, Patient's Right and Cutural Factors. Eubios Journal of Asian and International Bioethics 5, 87-90.

National Bioethics Advisory Commission

1997 Cloning Human Beings: Report and Recommendations of the National Bioethics Advisory Commission. Rockland, MD.

Nelson, J.L.

1994 "Routine Organ Donation: A Communitarian Organ Procurement Policy." Responsive Community: Rights and Responsibilities 4(3): 63-68.

Radder, $\mathrm{H}$.

1996 In and About the World: Philosophical Studies of Science and Technology. New York: State University of New York Press.

Ramsey, P.

1970 Fabricated Man: The Ethics of Genetic Control. New Haven, CN: Yale University Press.

Sinsheimer, R.

1976 "The Prospect for Designed Genetic Change." American Scientist 57 (1): 143-142.

Teilhard de Chardin, P.

1959 The Phenomenon of Man. Translated from the French by Bernard Wall. New York, Harper.

1964 The Future of Man. Translated from the French by Norman Denny. New York, Harper \& Row.

Winner, L.

1977 Autonomous Technology: TechnicsOut-of-Control as a Theme in Political Thought. Cambridge, MA: MIT Press.

1986 The Whale and the Reactor: A Search for Limits in an Age of High Technology. Chicago. University of Chicago Press.

Wynne, B.

2002 Risk and Environment as Legitimatory Discourses of Technology: Reflexivity Inside Out? Current Sociology 50(3): 459-477.
Susan E. Kelly
Department of Sociology
University of Louisville, USA
skelly@louisville.edu 